\title{
Systemic air embolism causing acute stroke and myocardial infarction after percutaneous transthoracic lung biopsy-a case report
}

\author{
Wei-Heng Hung ${ }^{1}$, Chun-Chi Chang ${ }^{2 \dagger}$, Shang-Yun Ho ${ }^{3}$, Chiung-Ying Liao ${ }^{3}$ and Bing-Yen Wang ${ }^{1,4,5^{*}+}$
}

\begin{abstract}
Computed tomography (CT)-guided transthoracic lung biopsy is a common procedure for the diagnosis of pulmonary lesion. Pneumothorax, pulmonary hemorrhage and hemoptysis are the most common complications of the procedure. Air embolism is a rare serious complication. We reported a case with air embolism related acute ischemic stroke and non-ST elevation myocardial infarction (NSTEMI) simultaneously after percutaneous transthoracic lung biopsy.
\end{abstract}

Keywords: Air embolism, Biopsy, Stroke, Myocardial infarction

\section{Background}

Computed tomography (CT)-guided transthoracic lung biopsy is a common procedure for the diagnosis of pulmonary lesion. The procedure is usually safe but still not free of complications. Pneumothorax, pulmonary hemorrhage and hemoptysis are the most common complications. The serious complications such as air embolism sometimes occurred. The incidence has been reported to be $0.02 \%$ to $0.07 \%$ [1-3]. Air embolism is rare but potentially lifethreatening complication of CT-guided transthoracic lung biopsy. Air embolism could induce acute ischemic stroke or acute myocardial infarction and caused patient to death. We reported a case with air embolism related acute ischemic stroke and non-ST elevation myocardial infarction (NSTEMI) simultaneously after CT-guided transthoracic lung biopsy.

\section{Case presentation}

A 63-year-old man underwent a chest CT-guided biopsy of lung tumor in prone position (Fig. 1a). Subsequent chest CT demonstrated air-fluid in the aorta and air embolism in the coronary artery (Fig. 1b-c). Consciousness

\footnotetext{
* Correspondence: 156283@cch.org.tw

${ }^{\dagger}$ Equal contributors

'Division of Thoracic Surgery, Department of Surgery, Changhua Christian Hospital, No. 135, Nanxium St, Changhua City, Changhua County 500, Taiwan ${ }^{4}$ Division of Thoracic Surgery, Department of Surgery, Taipei Veterans General Hospital Taipei, and School of Medicine, National Yang-Ming University, Taipei, Taiwan

Full list of author information is available at the end of the article
}

disturbance with urine incontinence developed after lung biopsy immediately. Neurological examination revealed right hemiplegia with drowsy consciousness and global aphasia. Brain CT showed multiple air embolisms in the cerebral vessels (Fig. 1e). Post-lung biopsy air emboli related acute ischemic stroke over left middle cerebral artery territory was impressed. Cold sweating developed at the same night. Elevated cardiac enzymes levels were noted. Electrocardiography also showed ST-segment depression in leads II, III and aVF. (Fig. 1d). Air emboli related nonST elevation myocardial infarction (NSTEMI) was found. Conservative treatment with aspirin used, intravenous fluid hydration and oxygen therapy with $\mathrm{FiO} 250 \%$ were administrated. Right hemiplegia improved gradually and cardiac enzymes level also subsided. The patient was discharged smoothly 7 days after lung biopsy.

\section{Discussion}

Air embolism is a rare complication of the CT-guided lung biopsy and is potentially fatal. Air can enter a pulmonary vein branch either directly via the entry needle of a coaxial system or through a fistulous connection (created during the biopsy) between an airway and adjacent pulmonary vein. The air bubble may then pass into the left heart and subsequently occlude to the coronary or cerebral circulation. This could result in myocardial infarction or stroke. The risk of air embolism is increased in the biopsy of more central lung lesions due to the increased diameter of the bronchovascular bundle [4]. 


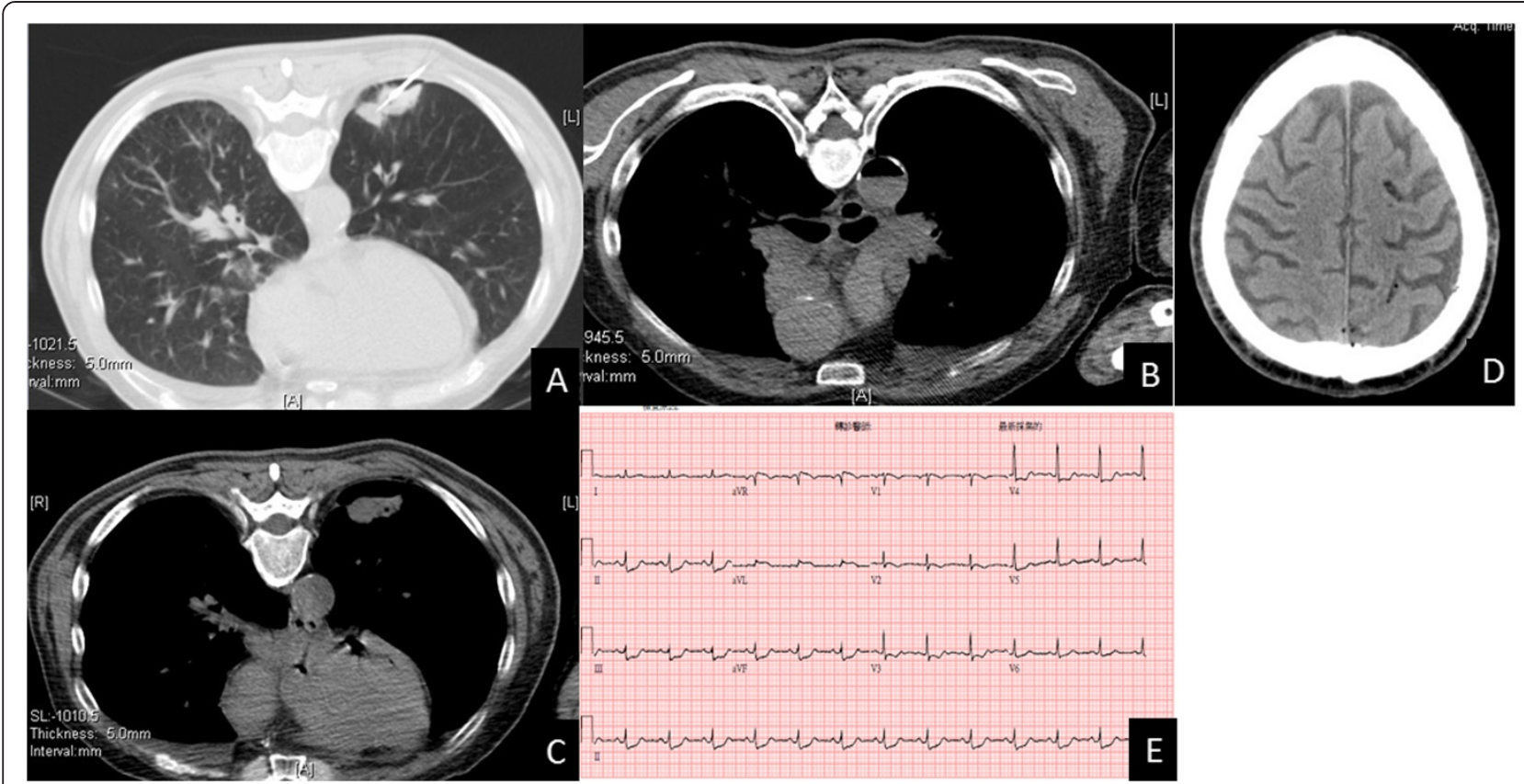

Fig. 1 a Transthoracic biopsy with $18 \mathrm{G}$ coaxial niddle for a pulmonary tumor. b Chest computed tomography revealed air-fluid in the aorta. c Chest computed tomography showed air bubbles in the coronary artery. $\mathbf{d}$ Brain computed tomography demonstrated multiple air embolisms in the cerebral vessels. e Electrocardiography also showed ST-segment depression in leads II, III and aVF

Air embolism may be prevented by avoiding needle biopsies of cysts, cavities, or bullous lung parenchyma. In addition, a stylet or occlusion of the hollow needle at all times can prevent direct communication between the atmosphere and pulmonary venous system. The patient should refrain from coughing or straining while the mass is being biopsied, especially when the stylet has been removed. It is crucial to select an insertion site where the needle penetrates the least amount of lung parenchyma to reach the mass. Performing the biopsy under CT-guided fluoroscopy may decrease the incidence of this complication [5]. Freund et al. [6] found the depth of the needle in the lesion (Needle tip not in the tumor is risk factor), endotracheal anesthesia, location of the lesion above the level of the left atrium, and prone position of the patients were independent risk factors for the incidence of a systemic air embolism. In our case, the lesion was under the level of the left atrium. The procedure was performed under local anesthesia and the needle tip was in the tumor. But the patient was positioned in prone position. Prone position could be the risk factor of systemic air embolism in our case.

In previous studies [7-11], hyperbaric oxygen therapy has been considered the primary therapy by reducing bubble volume and improving tissue oxygenation. The size of a gas bubble is inversely proportional to ambient pressure at constant temperature. In our case, the patient did not receive hyperbaric oxygen therapy but other conservative treatment; he was still discharged smoothly 7 days after lung biopsy.

\section{Conclusion}

Although the incidence rate of air embolism is low after CT-guided transthoracic lung biopsy, its potential mortality should be respected.

\section{Consent}

Written informed consent was obtained from the patient for publication of this Case report and any accompanying images. A copy of the written consent is available for review by the Editor-in-Chief of this journal.

\section{Abbreviations}

CT: Computed tomography; NSTEMI: Non-ST elevation myocardial infarction.

\section{Competing interests}

The authors declare that they have no competing interests.

\section{Authors' contributions}

WH and BW reviewed the medical record and drafted the manuscript. SY provided the image. CY performed the procedure of lung biopsy. CC provided the clinical expertise on the case. All authors have read and approved the manuscript.

\section{Acknowledgement}

The authors thank department of Neurology for patient care after air embolism related acute ischemic stroke was noted.

\section{Author details}

'Division of Thoracic Surgery, Department of Surgery, Changhua Christian Hospital, No. 135, Nanxium St, Changhua City, Changhua County 500, Taiwan. ${ }^{2}$ Division of Chest Medicine, Department of Internal Medicine, Changhua Christian Hospital, Changhua, Taiwan. ${ }^{3}$ Department of Medical Imaging, Changhua Christian Hospital, Changhua, Taiwan. ${ }^{4}$ Division of Thoracic Surgery, Department of Surgery, Taipei Veterans General Hospital Taipei, and School of Medicine, National Yang-Ming University, Taipei, 
Taiwan. ${ }^{5}$ Institutes of Medicine, Chung Shan Medical University, Taichung, Taiwan.

Received: 18 April 2015 Accepted: 4 September 2015

Published online: 15 September 2015

References

1. Sinner WN. Complications of percutaneous transthoracic needle aspiration biopsy. Acta Radiol Diagn (Stockh). 1976;17:813-28.

2. Richardson CM, Pointon KS, Manhire AR, Macfarlane JT. Percutaneous lung biopsies: a survey of UK practice based on 5444 biopsies. Br J Radiol. 2002;75:731-5

3. Tomiyama N, Yasuhara $Y$, Nakajima $Y$, Adachi S, Arai $Y$, Kusumoto M, et al. CT-guided needle biopsy of lung lesions: a survey of severe complication based on 9783 biopsies in Japan. Eur J Radiol. 2006;59:60-4.

4. Hiraki T, Fujiwara H, Sakurai J, Iguchi T, Gobara H, Tajiri N, et al. Nonfatal systemic air embolism complicating percutaneous CT-guided transthoracic needle biopsy: four cases from a single institution. Chest. 2007;132:684-90.

5. Worth ER, Burton JR, Landreneau RJ, Eggers Jr GW, Curtis JJ. Left arterial air embolism during intraoperative needle biopsy of a deep pulmonary lesion. Anesthesiology. 1990;73:342-5.

6. Freund MC, Petersen J, Goder KC, Bunse T, Wiedermann F, Glodny B. Systemic air embolism during percutaneous core needle biopsy of the lung: frequency and risk factors. BMC Pulm Med. 2012;12:2.

7. Bacha S, Annane D, Gajdos P. latrogenic air embolism. Presse Med. 1996;25:1466-72

8. Dutka AJ. A review of the pathophysiology and potential application of experimental therapies for cerebral ischemia to the treatment of cerebral arterial gas embolism. Undersea Biomed Res. 1985;12:403-21.

9. Kindwall EP. Massive surgical air embolism treated with brief recompression to six atmospheres followed by hyperbaric oxygen. Aerosp Med. 1973;44:663-6.

10. McDermott JJ, Dutka AJ, Koller WA, Pearson RR, Flynn ET. Comparison of two recompression profiles in treating experimental cerebral air embolism. Undersea Biomed Res. 1992;19:171-85.

11. Shetty PG, Fatterpekar GM, Manohar S, Sujit V, Varsha J, Zarir U. Fata cerebral air embolism as a complication of transbronchoscopic lung biopsy: a case report. Australas Radiol. 2001;45:215-7.

\section{Submit your next manuscript to BioMed Central and take full advantage of:}

- Convenient online submission

- Thorough peer review

- No space constraints or color figure charges

- Immediate publication on acceptance

- Inclusion in PubMed, CAS, Scopus and Google Scholar

- Research which is freely available for redistribution 